\title{
A highly thermotolerant laccase produced by Cerrena unicolor strain CGMCC 5.1011 for complete and stable malachite green decolorization
}

\author{
Yanhua Yao ${ }^{1}$, Guimei Zhou' ${ }^{1}$ Yonghui Lin ${ }^{2}$, Xinqi Xu ${ }^{1 *}$ and Jie Yang ${ }^{1 *}$
}

\begin{abstract}
Laccases are a class of multi-copper oxidases with important industrial values. A thermotolerant laccase produced by a basidiomycete fungal strain Cerrena unicolor CGMCC 5.1011 was studied. With glycerin and peptone as the carbon and nitrogen sources, respectively, a maximal laccase activity of $121.7 \mathrm{U} / \mathrm{mL}$ was attained after cultivation in the shaking flask for 15 days. Transcriptomics analysis revealed an expressed laccase gene family of 12 members in C. unicolor strain CGMCC 5.1011, and the gene and CDNA sequences were cloned. A glycosylated laccase was purified from the fermentation broth of Cerrena unicolor CGMCC 5.1011 and corresponded to Lac2 based on MALDI-TOF MS/MS identification. Lac2 was stable at pH 5.0 and above, and was resistant to organic solvents. Lac2 displayed remarkable thermostability, with half-life time of $1.67 \mathrm{~h}$ at $70^{\circ} \mathrm{C}$. Consistently, Lac2 was able to completely decolorize malachite green $(\mathrm{MG})$ at high temperatures, whereas Lac7 from Cerrena sp. HYB07 resulted in accumulation of colored MG transformation intermediates. Molecular dynamics simulation of Lac2 was conducted, and possible mechanisms underlying Lac2 thermostability were discussed. The robustness of C. unicolor CGMCC 5.1011 laccase would not only be useful for industrial applications, but also provide a template for future work to develop thermostable laccases.
\end{abstract}

Keywords: Cerrena unicolor, laccase, purification, Thermostability, Malachite green

\section{Key points}

1. C. unicolor strain CGMCC 5.1011 produced $122 \mathrm{U} /$ mL laccase.

2. The strain contained 12 expressed laccase isozymes.

3. A novel, thermostable laccase, Lac2, was purified and characterized.

4. Lac2 decolorized malachite green at 50 and $70{ }^{\circ} \mathrm{C}$ whereas another laccase failed.

*Correspondence: xuxinqi@fzu.edu.cn;T09136@fzu.edu.cn

1 Fujian Key Laboratory of Marine Enzyme Engineering, College

of Biological Sciences and Technology, Fuzhou University, Fuzhou 350116,

Fujian, China

Full list of author information is available at the end of the article

\section{Introduction}

Laccases (EC 1.10.3.2) are copper-containing oxidases catalyzing oxidation of phenolic/non-phenolic ligninrelated compounds and recalcitrant environmental pollutants (Baldrian 2006; Couto and Herrera 2006). Because laccases have low substrate specificity, utilize oxygen as final electron acceptor and produce water as only by-product, they find applications in paper pulping and bleaching, textile refining, dye decolorization, bioremediation, organic synthesis, juice and wine clarification, etc. (Ai et al. 2015; Yang et al. 2017a) Nonetheless, laccase applications are hampered by low production yields and reduced performance under industrial conditions such as high temperatures (Yang et al. 2017a).

Laccases are widespread in nature; they are found in microorganisms, plants and animals, and white-rot 
fungi are considered the most efficient laccase producers (Arora and Sharma 2010; Couto and Toca-Herrera 2007). Although the Cerrena genus is not as intensively studied as Trametes, Cerrena species have gained attention as laccase producers (Chen et al. 2012; Yang et al. 2017a). We have previously reported a Cerrena sp. HYB07 with high laccase yields; Lac7 is the laccase predominantly produced by HYB07 (Yang et al. 2014, 2015a, 2016b) and is active towards a wide range of substrates, including dyestuffs and antibiotics (Yang et al. 2015b, 2016a, 2016c, 2016d). In the present work, we continued our quest for laccase-secreting Cerrena and investigated a C. unicolor strain CGMCC 5.1011. Transcriptomics and cloning revealed a laccase gene family of 12 members in C. unicolor CGMCC 5.1011. Lac2 was purified from the fermentation broth and displayed extraordinary thermostability. Lac2 was able to decolorize the triphenylmethane dye malachite green (MG) despite incomplete decolorization by Lac7 from Cerrena sp. HYB07 due to heat inactivation. The research presented herein provided a novel laccase with thermotolerance and thermostability that would be desirable for industrial applications.

\section{Materials and methods}

\section{Strain and media}

C. unicolor strain CGMCC 5.1011 was purchased from China General Microbiological Culture Collection Center and maintained on potato dextrose agar (PDA) at $4{ }^{\circ} \mathrm{C}$. The fermentation medium for strain 5.1011 contained $(\mathrm{g} / \mathrm{L}): \mathrm{KH}_{2} \mathrm{PO}_{4} 6 \mathrm{~g}, \mathrm{MgSO}_{4} \cdot 7 \mathrm{H}_{2} \mathrm{O} 4.14 \mathrm{~g}, \mathrm{CaCl}_{2}$ $0.3 \mathrm{~g}, \mathrm{NaCl} 0.18 \mathrm{~g}, \mathrm{CuSO}_{4} \cdot 5 \mathrm{H}_{2} \mathrm{O} 0.0625 \mathrm{~g}, \mathrm{ZnSO}_{4} \cdot 7 \mathrm{H}_{2} \mathrm{O}$ $0.018 \mathrm{~g}$, VB1 $0.15 \mathrm{~g}$ and respective carbon and nitrogen sources. The following carbon sources were tested at $2.0 \%(\mathrm{w} / \mathrm{v})$ : Mannitol, glycerol, glucose, lactose, sucrose, cellulose, maltodextrin, corn dextrin, $\beta$-dextrin, soluble starch, corn starch, in combination with $1.5 \%(\mathrm{w} / \mathrm{v})$ peptone. Next, the following nitrogen source were tested at the level of $1.5 \%(\mathrm{w} / \mathrm{v})$ : ammonium nitrate, ammonium tartrate, peptone, yeast extract, beef extract, ammonium sulphate, and soybean cake powder. The concentrations of the nutrient sources were also optimized. Fermentation of Cerrena sp. strain HYB07 was carried out as described (Yang et al. 2015a).

\section{Transcriptomics analysis of C. unicolor CGMCC 5.1011}

Mycelia were collected from 6-d-old C. unicolor CGMCC 5.1011, and total RNA was extracted with a RNeasy Plant Mini Kit (Qiagen, Hilden, Germany). Transcriptomics analysis was performed by Novogene (Beijing, China). Briefly, after RNA quality check, $3 \mu \mathrm{g}$ RNA was used as input material. Sequencing libraries were generated using NEBNext Ultr RNA Library Prep Kit for Illumina (NEB, Ipswich, MA, USA). After cluster generation, the library preparations were sequenced on an Illumina Hiseq platform and paired-end reads were generated; then data analysis, gene function was annotated based on the following databases: Nr, Nt, Pfam, KOG/COG, Swiss-Prot, $\mathrm{KO}$, and $\mathrm{GO}$.

\section{Cloning of laccase genes and cDNA}

DNA was extracted with E.Z.N.A. HP Fungal DNA Kit (Omega, Norcross, GA, USA). TransScript One-Step Removal and cDNA Synthesis SuperMix (TransGen Biotech, Beijing, China) was used to synthesize the first strands of cDNA. PCR was carried out with $2 \times$ EasyTaq PCR SuperMix (TransGen Biotech, Beijing, China). Thermal asymmetric interlaced PCR (TAIL-PCR) was used to clone the flanking sequences of incomplete laccase genes. Primers used are listed in Supplementary Table S1. PCR products were inserted into pMD18-T vector (Takara, Dalian, China), and the recombinant vectors were transformed into E. coli TOP10 competent cells (Life Technologies, Grand Island, NY, USA). Four clones of each PCR product were randomly selected and submitted to sequencing analysis.

\section{Bioinformatic analysis}

Sequences were analyzed by using BLAST (Altschul 1990). Signal peptide was predicted with SignalP 3.0 (Bendtsen et al. 2004). Potential $N$-glycosylation sites (Asn-X-Ser/Thr) were identified with ScanProsite (Edouard et al. 2006). Alignments of laccase proteins were generated with Clustal Omega (Sievers et al. 2011). Phylogeny tree of selected fungal laccases were calculated in MEGA version 7.0 (Tamura 2011). Hydrophobic interaction and salt bridges were predicted by Protein Interactions Calculator (PIC) web server (Tina et al. 2007). Three-dimensional structures were visualized and analyzed by using PyMOL Molecular Graphics System (Version 1.80, Schrödinger, LLC) (Lam 2016).

\section{Enzyme activity assay}

Laccase activity was assayed with ABTS $\left(\varepsilon=36,000 \mathrm{M}^{-1} \mathrm{~cm}^{-1}\right)$, guaiacol $\left(\varepsilon=26,600 \mathrm{M}^{-1} \mathrm{~cm}^{-1}\right)$ or catechol $\left(\varepsilon=1260 \mathrm{M}^{-1} \mathrm{~cm}^{-1}\right)$ as the substrate by following absorbance change at 420, 470 and $400 \mathrm{~nm}$, respectively. One unit of enzyme activity was defined as the amount of enzyme needed to oxidize $1 \mu \mathrm{mol}$ substrate in $1 \mathrm{~min}$. All measurements were carried out in triplicate.

\section{Protein purification and characterization}

The fermentation broth was harvested by centrifugation at $12,000 \mathrm{~g}$ for $10 \mathrm{~min}$ and then filtered. The precipitate formed with $50 \%$ to $90 \%\left(\mathrm{NH}_{4}\right)_{2} \mathrm{SO}_{4}$ was collected by centrifugation $(20,000 \mathrm{~g}, 20 \mathrm{~min})$, resuspended in buffer $\mathrm{A}$ (50 mM Tris- $\mathrm{HCl}$ buffer, $\mathrm{pH}$ 8.0) and dialyzed in buffer 
A. The dialyzed crude enzyme solution was applied at $5 \mathrm{~mL} / \mathrm{min}$ to a HiTrap DEAE column pre-equilibrated with buffer A. Adsorbed proteins were eluted with 0.15 $\mathrm{NaCl}$ in buffer $\mathrm{A}$. The purified protein was analyzed by SDS-PAGE for homogeneity and stained with Coomassie Brilliant Blue R-250. Deglycosylation was carried out with Peptide $\mathrm{N}$-glycosidase F (Takara, Dalian, China) according to manufacturer's instructions. Protein identification with MALDI-TOF MS/MS was performed by APT SHANGHAI Applied Protein Technology (Shanghai, China).

\section{Enzymatic characterization of the purified laccase}

The effect of $\mathrm{pH}$ on laccase activity was determined between $\mathrm{pH} 2.5$ to 6.5 at $40^{\circ} \mathrm{C}$. $\mathrm{pH}$ stability was studied by incubating the enzyme at $\mathrm{pH} 2.5-9.0$ at $30^{\circ} \mathrm{C}$ for $48 \mathrm{~h}$. Residual laccase activity was quantified with ABTS as the substrate. Buffers used included citrate-phosphate buffer (pH 2.5-8.0), and glycine- $\mathrm{NaOH}$ buffer ( $\mathrm{pH} 9.0$ ).

For optimum temperature, laccase activity was measured at the optimum $\mathrm{pH}$ and temperatures from 20 to $70{ }^{\circ} \mathrm{C}$. Thermostability was analyzed by incubating the enzyme at different temperatures $\left(40-70{ }^{\circ} \mathrm{C}\right)$, and residual activity was assayed with ABTS at optimum $\mathrm{pH}$ and temperature. All experiments were performed in triplicate.

Effect of metal ions on activity of the purified enzyme was investigated. Metal ions $\mathrm{Al}^{3+}, \mathrm{Ca}^{2+}, \mathrm{Ce}^{3+}, \mathrm{Cu}^{2+}, \mathrm{Fe}^{2+}$, $\mathrm{K}^{+}, \mathrm{Li}^{+}, \mathrm{Mg}^{2+}, \mathrm{Mn}^{2+}$ and $\mathrm{Zn}^{2+}$ were in form of sulfate, $\mathrm{Cd}^{2+}, \mathrm{Hg}^{2+}, \mathrm{Ni}^{2+}$ and $\mathrm{Co}^{2+}$ in form of nitrate, and $\mathrm{Pb}^{2+}$ in form of subacetate. Individual inhibitor or metal ion was incorporated in the enzyme assay, and activity was determined with ABTS at optimal temperature and $\mathrm{pH}$. Enzyme activity in absence of metal ions was regarded as $100 \%$.

Organic solvents, namely methanol, ethanol, acetone, isopropanol, acetonitrile and dimethyl sulfoxide (DMSO), was added individually to the enzyme activity assay to the final concentration of $10 \%$ or $25 \%$, and the laccase activity assay was carried out at the optimal temperature and $\mathrm{pH}$ with ABTS as the substrate. Enzyme activity in absence of organic solvents was regarded as $100 \%$.

\section{MG decolorization}

Decolorization of MG was carried out at 30,50 and $70{ }^{\circ} \mathrm{C}$ with laccase from C. unicolor strain CGMCC 5.1011 and Cerrena sp. HYB07, respectively. The decolorization mixture contained $50 \mathrm{mM}$ citrate-phosphate buffer $(\mathrm{pH}$ 6.0), $100 \mathrm{mg} / \mathrm{L}$ MG and $20 \mathrm{U} / \mathrm{mL}$ laccase. The mixture with heat-inactivated laccase was used as the negative control. After decolorization, the reaction mixtures were subjected to UV-visible analysis with a Hitachi U-2910 UV-Vis spectrophotometer (Chiyoda, Tokyo, Japan).
Decolorization efficiency was monitored at $618 \mathrm{~nm}$ and calculated with the following formula:

$$
\text { Decolorization efficiency }(\%)=\left(A_{0}-A_{1}\right) / A_{0} \times 100 \text {, }
$$

where $A_{0}$ and $A_{1}$ are the absorption of MG before and after laccase treatment, respectively.

\section{Molecular dynamics (MD) simulation}

Homologous modeling was conducted with Phyre2 (Kelley et al. 2015), and MD simulation was carried out with BIOVIA Discovery Studio software (BIOVIA 2015). Solvation of the laccase protein was performed in CHARMm force field. Then standard dynamics cascade, including energy minimization for solvent, ions, protein and the whole system, heating, equilibration and MD production was done by the Discovery Studio software. The time for equilibration was $20 \mathrm{ps}$, and the time for MD production was 200 ps. The MD data was analyzed using Analyze Trajectory to obtain Root Mean Square Deviation (RMSD) and Root Mean Square Fluctuation (RMSF).

\section{Results}

Laccase production by C. unicolor CGMCC 5.1011

C. unicolor strain CGMCC 5.1011 was verified by $18 \mathrm{~s}$ rDNA sequencing. Among 11 carbon sources, glycerin was found to be the optimal carbon source, with the highest laccase activity of $121.7 \mathrm{U} / \mathrm{mL}$ at day 15 (Fig. 1a). Next, different concentrations of glycerin was used, and laccase production was followed (Fig. 1b). With 1.0\% glycerin, the peak of $40.4 \mathrm{U} / \mathrm{ml}$ was reached at day 11 . At higher glycerin concentrations of $3.0 \%$ and $5.0 \%$, greatest laccase yields of 63.7 and $29.8 \mathrm{U} / \mathrm{ml}$, respectively, were observed at day 17 . Therefore, $2.0 \%$ was determined as the optimal glycerin concentration. Among the nitrogen sources tested, organic nitrogen sources were more effective than inorganic nitrogen sources. Peptone resulted in the highest activity, followed by beef extract, soybean cake powder, ammonium tartrate (Fig. 1c). Furthermore, $1.5 \%$ peptone resulted in the highest activity, followed by $1.0 \%$ (Fig. 1d).

\section{The laccase gene family of $C$. unicolor CGMCC 5.1011}

Information on the transcriptome of C. unicolor CGMCC 5.1011 could be found in Additional file 1: Tables S2 and S3, and Fig. S1. A total of 12 laccase genes were identified and confirmed by the DNA and cDNA sequences (Table 1). The length of the nucleotide sequences for the twelve laccase genes ranged from 1652 (for Lac12) to 2406 bp (for Lac9). The deduced protein sequences of the 12 laccases were of length typical of fungal laccases (from 371 aa for Lac12 to 627 aa for Lac9), and all were predicted to contain a signal 

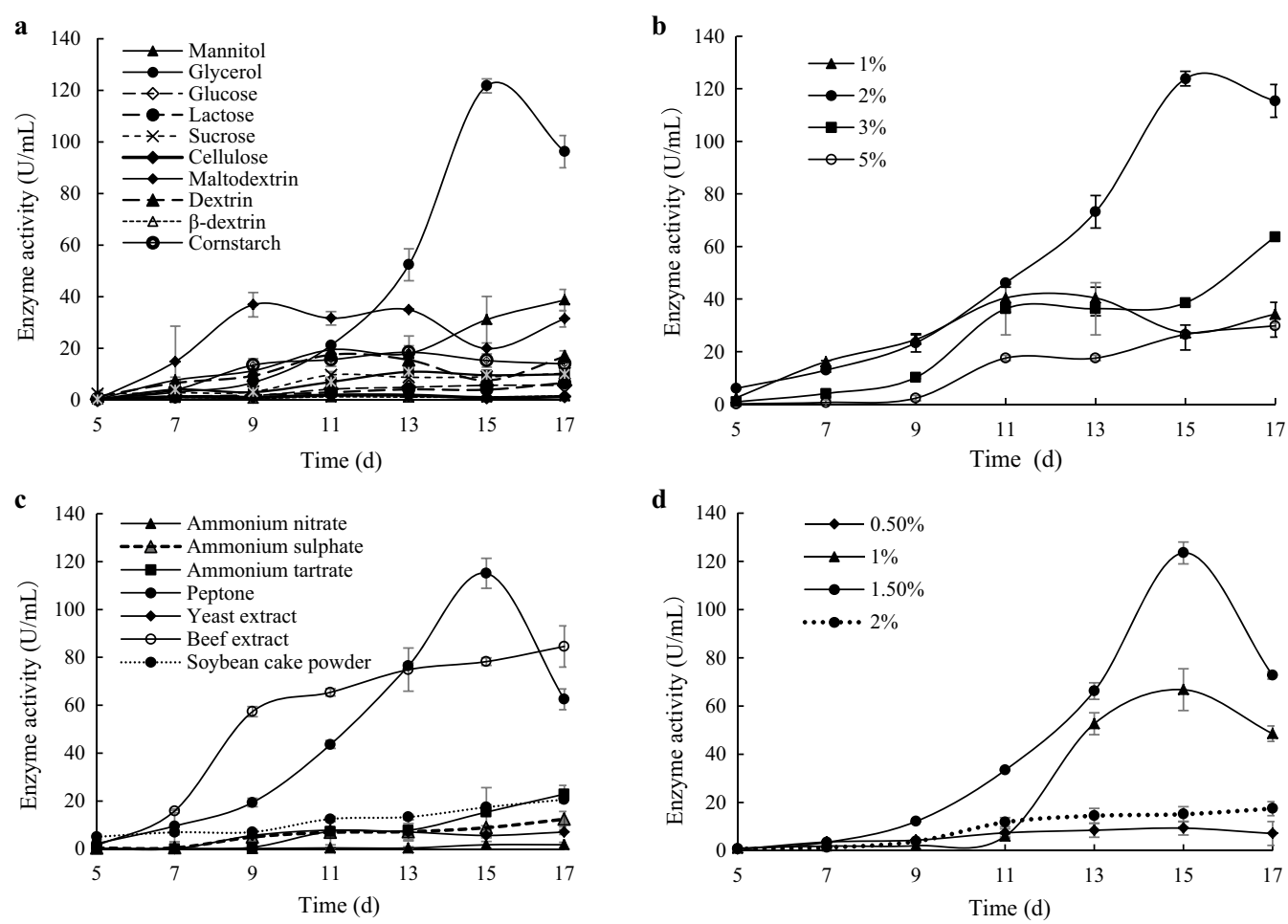

Fig. 1 Laccase production by C. unicolor CGMCC 5.1011. a Effect of carbon sources on laccase production. $\mathbf{b}$ Effect of glycerol concentration on laccase production. $\mathbf{c}$ Effect of nitrogen sources on laccase production. $\mathbf{d}$ Effect of peptone concentration on laccase production

Table 1 The C. unicolor CGMCC 5.1011 laccase gene family

\begin{tabular}{|c|c|c|c|c|c|c|c|}
\hline Laccase & $\begin{array}{l}\text { GenBank } \\
\text { Accession No }\end{array}$ & DNA length (bp) & $\begin{array}{l}\text { cDNA length } \\
\text { (bp) }\end{array}$ & $\begin{array}{l}\text { Intron } \\
\text { number }\end{array}$ & $\begin{array}{l}\text { Signal peptide } \\
\text { (aa) }\end{array}$ & $\begin{array}{l}\text { Mature protein } \\
\text { (aa) }\end{array}$ & $\begin{array}{l}\text { Glycosylation } \\
\text { sites }\end{array}$ \\
\hline Lac1 & MT210509 & 2173 & 1554 & 11 & 20 & 497 & 3 \\
\hline Lac2 & MT066188 & 2265 & 1599 & 12 & 20 & 512 & 13 \\
\hline Lac3 & MT210510 & 1858 & 1509 & 6 & 20 & 482 & 8 \\
\hline Lac4 & MT210511 & 2174 & 1548 & 11 & 19 & 496 & 4 \\
\hline Lac5 & МT386937 & 2223 & 1599 & 11 & 27 & 505 & 9 \\
\hline Lac6 & MT210513 & 2191 & 1551 & 11 & 21 & 495 & 3 \\
\hline Lac7 & MT210514 & 2202 & 1551 & 11 & 21 & 495 & 11 \\
\hline Lac8 & MT210515 & 2170 & 1551 & 11 & 21 & 495 & 5 \\
\hline Lac9 & MT246201 & 2406 & 1884 & 9 & 17 & 610 & 13 \\
\hline Lac10 & MT210516 & 2255 & 1596 & 12 & 20 & 511 & 12 \\
\hline Lac11 & MT246202 & 1836 & 1323 & 9 & 20 & 419 & 4 \\
\hline Lac12 & MT246203 & 1652 & 1116 & 8 & 14 & 357 & 9 \\
\hline
\end{tabular}

peptide. The intron numbers of the laccase isozymes varied between 6 and 12. A phylogenetic tree was constructed to show the evolutionary relationship of CGMCC 5.1011 laccases with reported laccases (Fig. 2).
Laccase purification and characterization

A laccase was purified from CGMCC 5.1011 fermentation broth after $\left(\mathrm{NH}_{4}\right)_{2} \mathrm{SO}_{4}$ precipitation and anion exchange chromatography. The protein appeared as a 


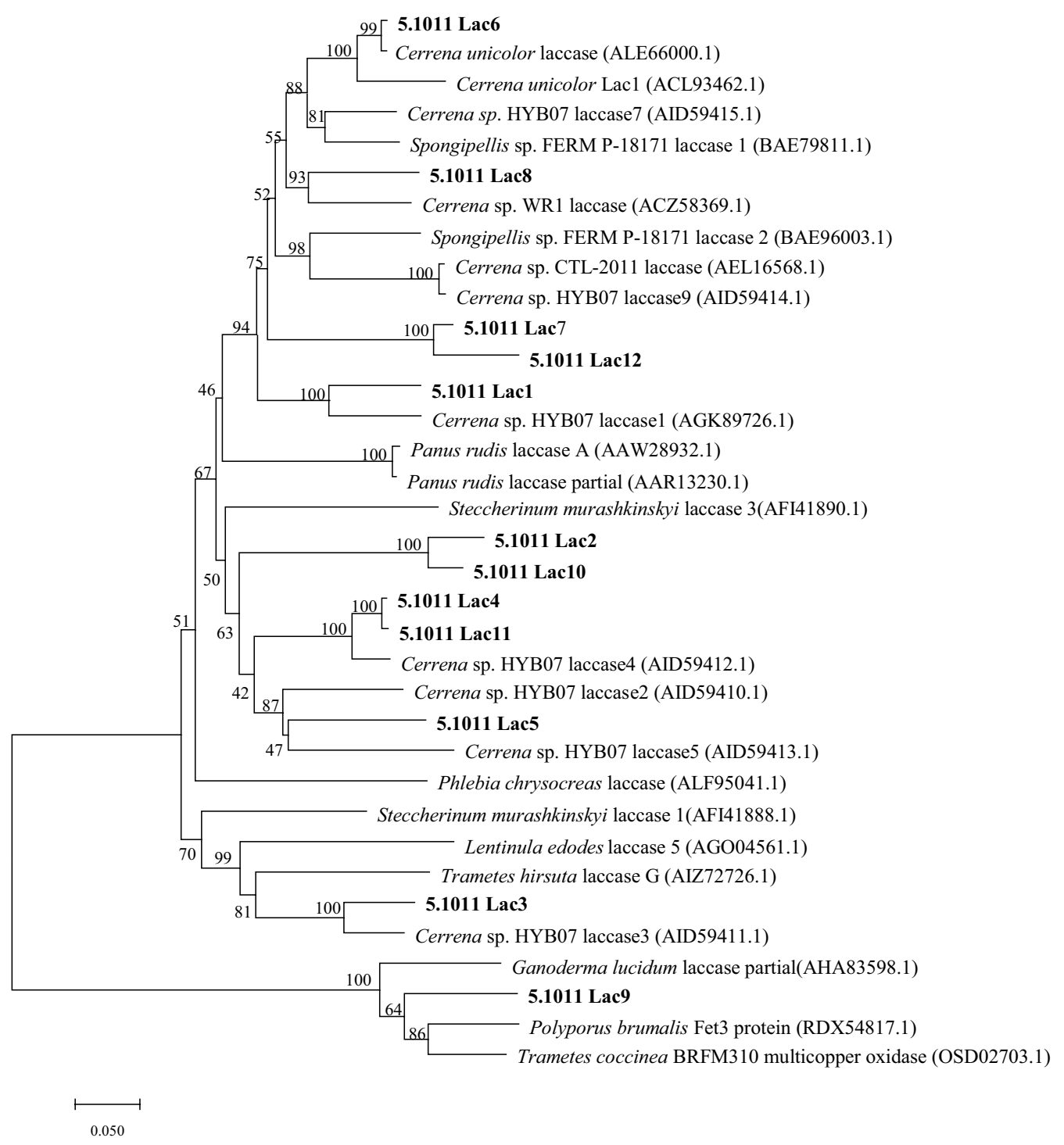

Fig. 2 Phylogenetic relationship of C. unicolor CGMCC 5.1011 laccases with reported laccases. The scale bar indicates the estimated number of amino acid substitutions per site

smear on SDS-PAGE between 58.4 and $74.0 \mathrm{kDa}$. After deglycosylation with peptide $\mathrm{N}$-glycosidase F, a single band was shown around $50 \mathrm{kDa}$, indicating the laccase was heterogeneously glycosylated (Fig. 3 ). The glycosylation extent was estimated to be $16.8 \%-48.0 \%$. The deglycosylated protein was subjected to MALDI-TOF MS/MS and was identified as Lac2 (Additional file 1: Fig. S2). The amino acid sequence of Lac2 was most similar to Lac4 from Cerrena sp. HYB07, sharing a 66\% identity (Additional file 1: Table S4).

\section{Enzymatic properties of Lac2}

The $\mathrm{pH}$ optimum was 3.0 for ABTS and 5.5 for catechol and 5.0 for guaiacol (Fig. 4a). Optimal temperature was $55{ }^{\circ} \mathrm{C}$ with ABTS, $45{ }^{\circ} \mathrm{C}$ with catechol and $60{ }^{\circ} \mathrm{C}$ with guaiacol. The enzyme displayed wide ranges of reacting temperatures, with $>50 \%$ of the maximal activity at $70{ }^{\circ} \mathrm{C}$ against the three substrates (Fig. 4b).

At pH 5.0 or higher, $>80 \%$ activity remained after $48 \mathrm{~h}$. In contrast, Lac2 was less stable at $\mathrm{pH} 2.5-4$ (Fig. 4c). Lac2 was also stable at different temperatures. After 


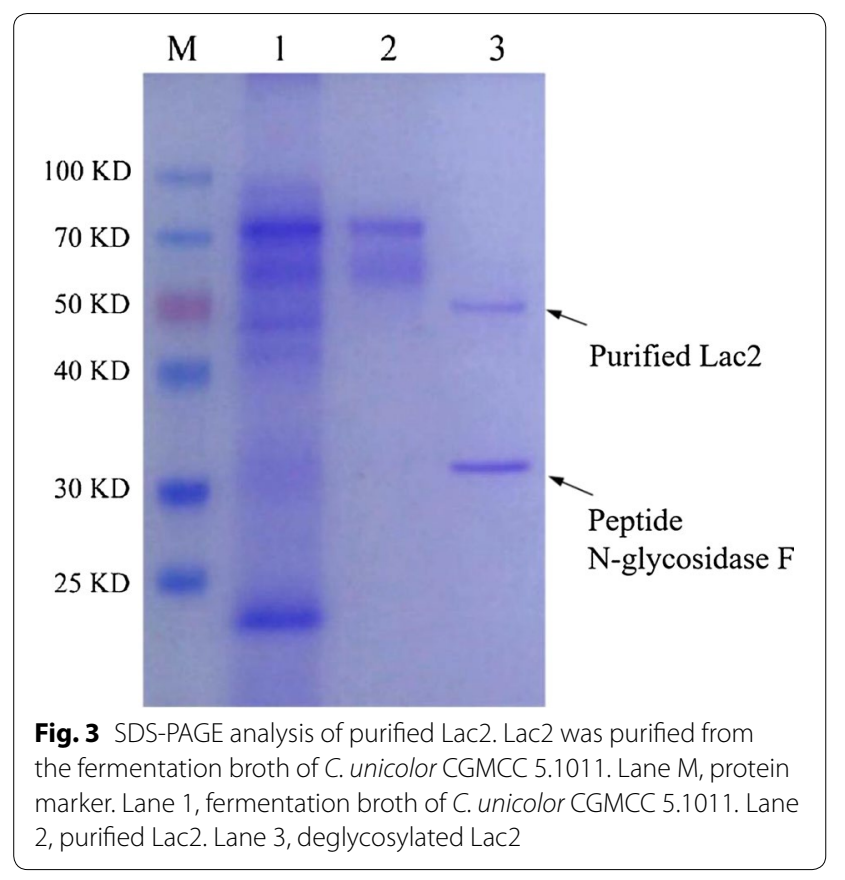

incubation for $11 \mathrm{~h}$ at 40,50 and $60^{\circ} \mathrm{C}$, approximately 80 , $70 \%$ and $50 \%$ of the original enzyme activity was retained, respectively (Fig. 4d). Heat inactivation rate $k$ increased with temperatures, accompanied by reduced half-life time $\left(t_{1 / 2}\right)$ (Table 2).

Effect of metal ions and organic solvents on Lac2 activity was also studied. At $10 \mathrm{mM}, \mathrm{Fe}^{2+}$ and $\mathrm{Hg}^{2+}$ exerted the strongest inhibition on Lac2 activity, followed by $\mathrm{Ce}^{3+}$. On the other hand, $\mathrm{Ca}^{2+}, \mathrm{K}^{+}, \mathrm{Mn}^{2+}, \mathrm{Pb}^{2+}$ and $\mathrm{Zn}^{2+}$ were stimulatory, and the rest metal ions showed no significant effect (Fig. 5a).

When individual water-miscible organic solvent was added to the final concentration of $10 \%$, Lac2 activity was similar to that in the absence of the organic solvents. Activity of Lac2 was compromised to different extents when the concentration was raised to $25 \%$; $>80 \%$ activity was retained in methanol and ethanol, followed by DMSO, isopropanol and acetone, whereas acetonitrile resulted in lowest activity of approximately $50 \%$ (Fig. 5b).
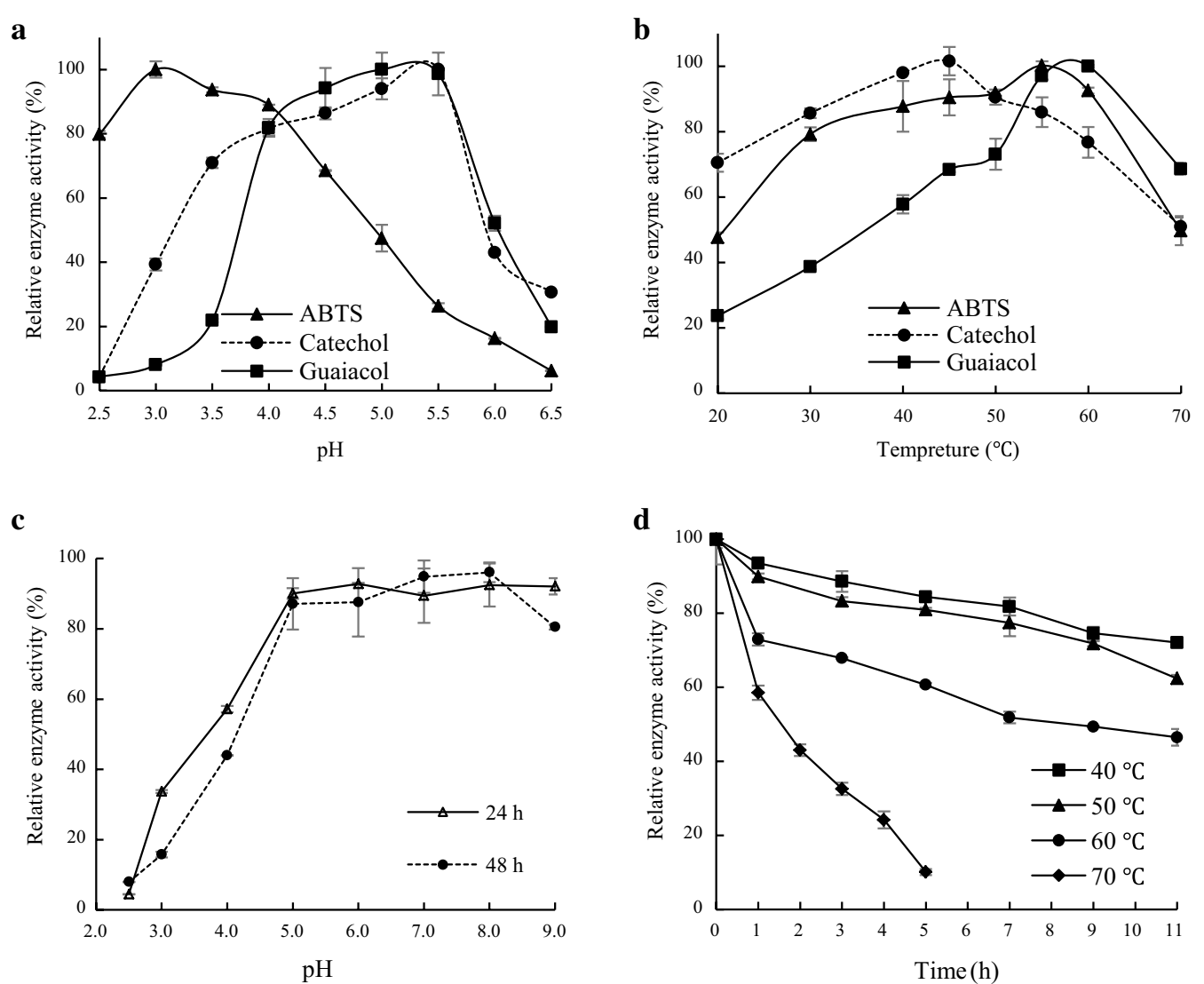

Fig. 4 Effect of pH and temperature on Lac2 activity and stability. $\mathbf{a}, \mathbf{b}$ Effect of $\mathrm{pH}$ and temperature on activity of Lac2. c, $\mathbf{d}$ Effect of pH and temperature on stability of Lac2 
Table 2 Thermal inactivation of Cerrena laccases

\begin{tabular}{|c|c|c|c|c|c|}
\hline Strain & Laccase & Temperature $\left({ }^{\circ} \mathrm{C}\right)$ & $t_{1 / 2}(\mathrm{~h})$ & $K\left(\mathrm{~h}^{-1}\right)$ & Reference \\
\hline Cerrena unicolor CGMCC 5.1011 & Lac2 & $\begin{array}{l}40 \\
50 \\
60 \\
70\end{array}$ & $\begin{array}{l}22.02 \\
16.85 \\
7.79 \\
1.67\end{array}$ & $\begin{array}{l}0.032 \\
0.041 \\
0.089 \\
0.414\end{array}$ & This study \\
\hline Cerrena sp. HYB07 & Lac7 & 70 & 0.13 & 5.42 & (Yang et al. 2017b) \\
\hline Cerrena unicolor strain 137 & $\begin{array}{l}\text { Lacc I } \\
\text { Lacc II }\end{array}$ & 70 & $\begin{array}{l}<0.17 \\
<0.33\end{array}$ & NR & (Michniewicz et al. 2006) \\
\hline Cerrena unicolor C-139 & & 70 & 0.25 & NR & (Songulashvili et al. 2012) \\
\hline Cerrena unicolor VKMF-3196 & $\begin{array}{l}\text { LacC1 } \\
\text { LacC2 }\end{array}$ & 70 & $\begin{array}{l}0.5 \\
0.05\end{array}$ & NR & (Zoya Alexandrovna et al. 2010) \\
\hline Cerrena sp.WR1 & Lcc3 & $\begin{array}{l}50 \\
60 \\
70\end{array}$ & $\begin{array}{l}2.0 \\
0.67 \\
0.13\end{array}$ & NR & (Chen et al. 2012) \\
\hline Cerrena unicolor BBP6 & LacA & $\begin{array}{l}60 \\
70\end{array}$ & $\begin{array}{l}<2.0 \\
<1.0\end{array}$ & NR & (Ji et al. 2018) \\
\hline Cerrena sp. RSD1 & DLac & 70 & $<0.17$ & NR & (Wu et al. 2018) \\
\hline
\end{tabular}

ABTS was used as the substrate

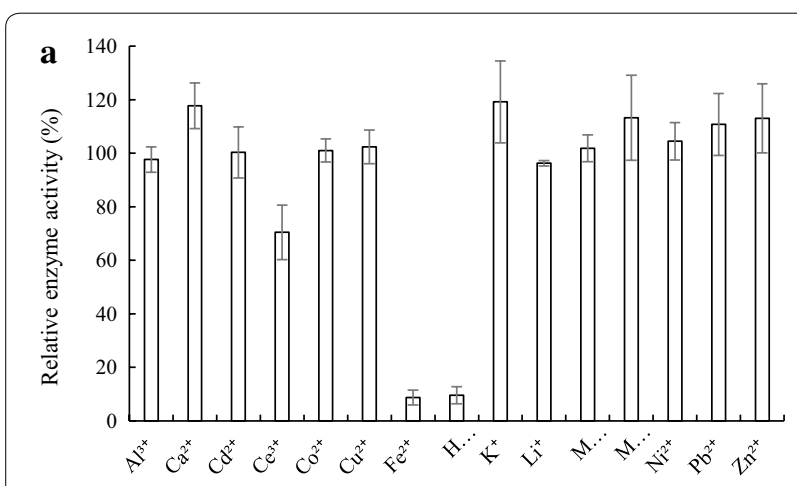

b

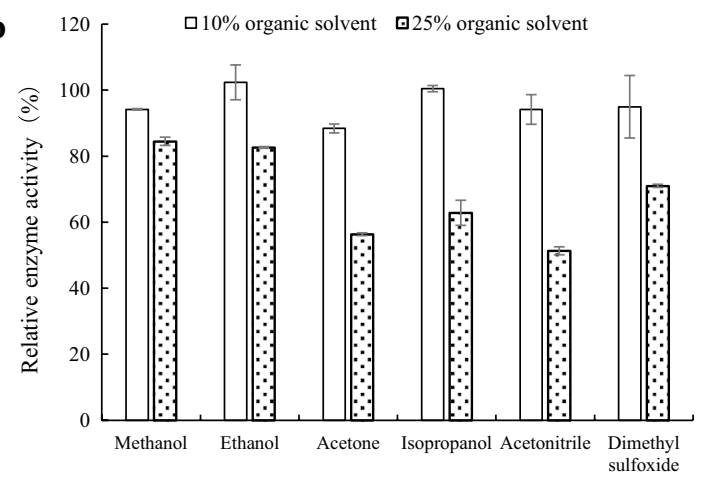

Fig. 5 Effect of metal ions $\mathbf{a}$ and organic solvents $\mathbf{b}$ on Lac2 activity

\section{MG decolorization}

To exemplify the operation stability offered by Lac2 thermostability, we compared Lac2 (from C. unicolor CGMCC 5.1011) and Lac7 (from Cerrena sp. HYB07) in MG decolorization, both in the absence of a redox mediator. We have previously shown MG is sequentially demethylated by laccase to colored intermediates desmethyl MG, didesmethyl MG, tridesmethyl MG and tetradesmethyl MG (Yang et al. 2015b).

At $30{ }^{\circ} \mathrm{C}$, two laccases performed similarly in MG decolorization (Fig. 6a-c). At $50^{\circ} \mathrm{C}$, despite similar decolorization efficiencies calculated by absorbance decreases at $618 \mathrm{~nm}$ (Fig. 6a), HYB07 Lac7 resulted in a recalcitrant pink color, accompanied by a shift of the absorbance peak from 618 to $560 \mathrm{~nm}$ (Fig. 6b-c). This was caused by accumulation of a stable, colored intermediate tetradesmethyl MG due to instability of the HYB07 Lac7 and thus perturbation of the MG demethylation pathway (Yang et al. 2017b). This phenomenon was not observed with C. unicolor CGMCC 5.1011 Lac2.

At $70{ }^{\circ} \mathrm{C}$, CGMCC 5.1011 Lac2 still accomplished MG decolorization without intermediate accumulation. HYB07 Lac7, on the contrary, was quickly inactivated and barely decolorized MG (Fig. $6 \mathrm{~b}$ and e). In fact, the shift of the absorbance peak to $590 \mathrm{~nm}$ was characteristic of a MG transformation product didesmethyl MG (Cho et al. 2003).

\section{Discussion}

In this study, C. unicolor CGMCC 5.1011 could produce high activity laccase and probably secreted the enzyme by secondary metabolism. This is thought to be an energysaving response common in laccase-producing fungi (Piscitelli et al. 2011; Yang et al. 2016b). Glycerin was the best carbon source for strain CGMCC 5.1011, and it also allowed for significant accumulation of laccase by Cerrena maxima, Fomes fomentarius and Pseudotrametes gibbosa. Some fungal strains prefer readily utilizable carbon sources. For example, HYB07 laccase expression 
a

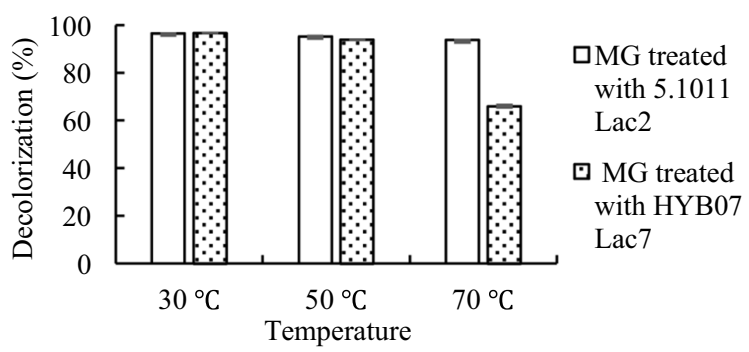

b
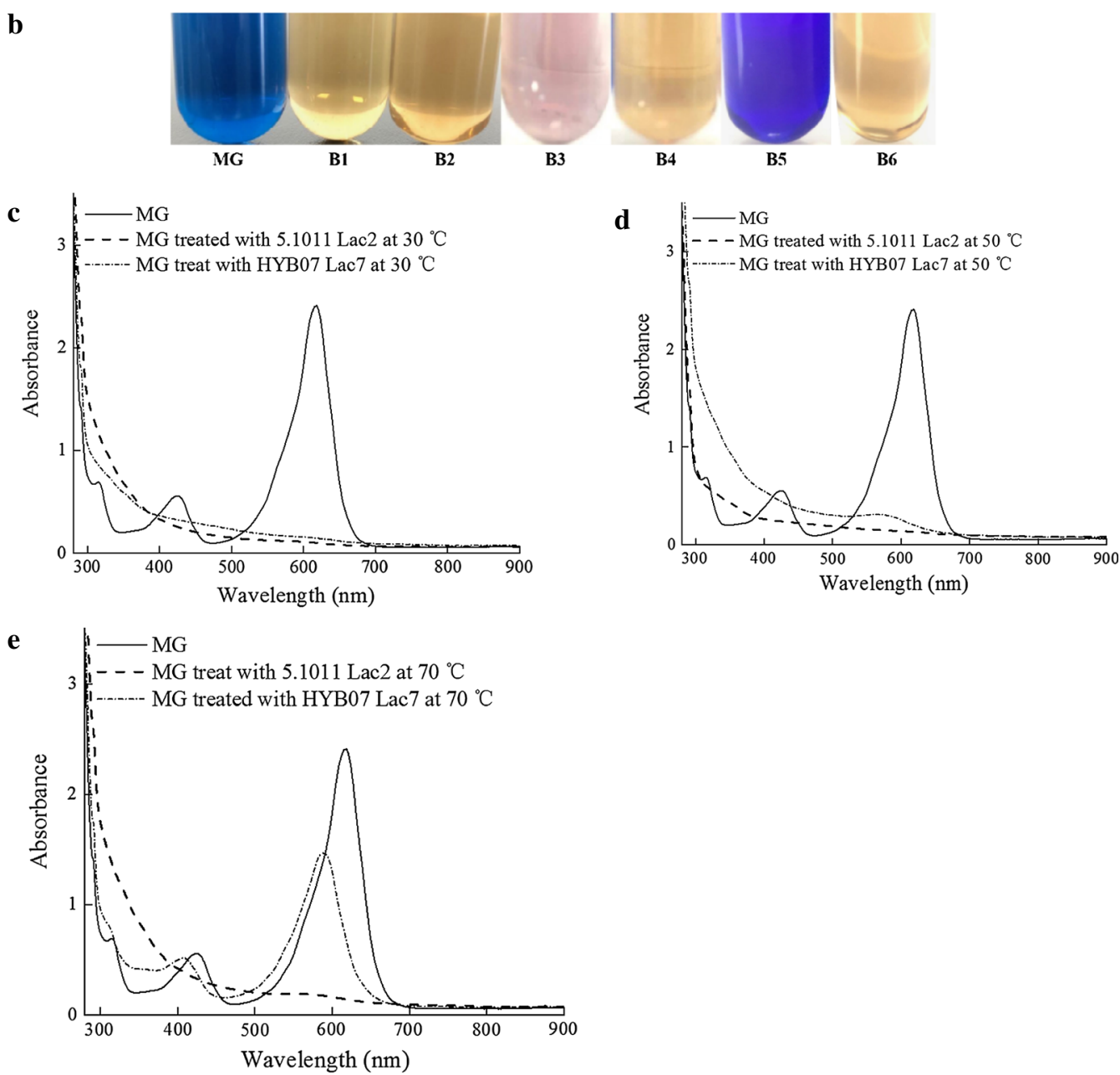

Fig. 6 Laccase-mediated decolorization of MG. a Decolorization efficiency of MG by laccases at 30, 50 and $70{ }^{\circ} \mathrm{C}$. b MG after laccases-mediated decolorization at different temperatures. B1, B3, B5: MG treated with HYB07 LaC7 at 30, 50 and $70^{\circ} \mathrm{C}$, respectively. B2, B4, B6: MG treated with CGMCC 5.1011 Lac2 at 30, 50 and $70{ }^{\circ} \mathrm{C}$, respectively. c-e UV-vis spectra of MG before and after decolorization by laccases at 30,50 and $70{ }^{\circ} \mathrm{C}$, respectively

is nearly abolished in the presence of glycerin as the sole carbon source (Yang et al. 2015a).

Fungal laccases exist in gene families, which may be derived from duplication-divergence events of a small set of ancestral enzymes. Laccase gene families have been analyzed in Pleurotus ostreatus, Lentinula edodes,
Coprinopsis cinerea, etc.; the family size varies from 5 to 17 (Yang et al. 2017a). The laccase family of Cerrena sp. HYB07 is composed of 13 laccase genes (Li 2017). Laccase genes of these two Cerrena species were similar in terms of size, intron number, and presence of signal peptide. However, the amino acid sequences of CGMCC 
5.1011 laccases seemed to contain more putative glycosylation sites (Asn-X-Ser/Thr, where X stands for any amino acid except for proline) than HYB07 laccases. CGMCC 5.1011 laccases were predicted to have 3-13 glycosylation sites per protein, with Lac2 having 13, while HYB07 laccases were predicted to contain 0-6 glycosylation sites per protein.

The major laccase secreted by CGMCC 5.1011, Lac2, was purified, and the enzymatic properties of purified Lac2 were studied. The optimal $\mathrm{pH}$ and $\mathrm{pH}$ stability of Lac2 were similar to those of reported fungal laccases, including Lac7 from Cerrena sp. HYB07 (Yang et al. 2014). On the other hand, the optimal reacting temperature of Lac2 was higher than that of Lac7. $\mathrm{Hg}^{2+}, \mathrm{Fe}^{2+}$, and $\mathrm{Ce}^{3+}$ inhibit activity of both CGMCC 5.1011 Lac2 and HYB07 Lac7; however, $\mathrm{Pb}^{2+}$ and $\mathrm{Li}^{+}$did not suppress Lac2 activity as they do to Lac7 (Xu et al. 2018; Yang et al. 2014). Lac2 was more tolerant of organic solvents compared with a thermo-active and thermostable laccase, Lac37 II, from Trametes trogii. In particular, approximately only $40 \%$ activity of Lac 37 II remains in the presence of $10 \%$ methanol (Yang et al. 2020).

Most remarkably, at $70{ }^{\circ} \mathrm{C}, t_{1 / 2}$ of Lac2 was $1.67 \mathrm{~h}$, which was longer than many reported laccases (Chen et al. 2012; Ji et al. 2018; Michniewicz et al. 2006; Songulashvili et al. 2012; Wu et al. 2018; Zoya Alexandrovna et al. 2010) and comparable to a thermostable laccase Lac37 II from T. trogii (Yang et al. 2020). A comparison of thermal inactivation of Cerrena laccases is provided in Table 2. The predominant laccase from Cerrena sp. HYB07, Lac7, was stable at $60{ }^{\circ} \mathrm{C}$ and below, but was completely inactivated in $20 \mathrm{~min}$ at $70{ }^{\circ} \mathrm{C}$ (Yang et al. 2014). The differences in thermostability of Lac2 from C. unicolor CGMCC 5.1011 and Lac7 from Cerrena sp. HYB07 could also be seen in their fluorescence spectra collected after incubating the respective proteins for $1 \mathrm{~h}$ at 30, 40, 50, 60, and $70{ }^{\circ} \mathrm{C}$ (Additional file 1: Fig. S3). With increased incubation temperatures, fluorescence spectra of Lac7 demonstrated significant decreases and red shift in fluorescence intensity at the emission peak, suggesting the protein was prone to lose its natural conformation at higher temperatures. In contrast, the fluorescent emission peaks of Lac2 remained relatively constant at different temperatures, consistent with its higher thermostability.

There are several putative molecular mechanisms underlying protein thermotolerance or thermostability (Hilden et al. 2009). An amino acid alignment of $C$. unicolor CGMCC 5.1011 Lac2 and Cerrena sp. HYB07 Lac7 showing the four conserved fungal laccase copperbinding signature domains (L1-L4) and six substratebinding loops (B1-B2, B4-B5, B7-B8, C1-C2, C4-C5, and $\mathrm{C} 7-\mathrm{C} 8$ ) is provided in Additional file 1: Fig. S5. We speculated that the thermostability of Lac2 can at least be partially attributed to its high glycosylation content. Glycosylation is suggested to have a general nonspecific effect on enzyme stabilization (Manuel et al. 2015; Shental-Bechor and Levy 2008; Vite-Vallejo et al. 2009). It has been reported that the high carbohydrate level (49\%) protected a Botrytis cinerea laccase from high-temperature denaturation (Slomczynski et al. 1995). Increased thermostability of a recombinant laccase (rLac) produced by Pichia pastoris compared to the native laccase (nLac) is also attributed to higher glycosylation, and the glycan moieties played a crucial role in the laccase activity (Garg et al. 2012). In this study, among the 13 potential glycosylation sites identified in CGMCC 5.1011 Lac2, 12 were found on the protein surface except for N71, which was near the protein surface and at the back of the active center (Additional file 1: Fig. S4). In contrast, only one putative glycosylation site was found on the surface of Lac7 from Cerrena sp. HYB07, which has a 7.2\% carbohydrate content (Yang et al. 2014), and Lac7 was inferior to Lac2 in CGMCC 5.1011 with regards to stability and performance at higher temperatures.

Hydrophobic interactions play a governing role in stabilizing the protein 3D structure (Christensen and Kepp 2012). Pace et al. argued that hydrophobic interactions made the most contribution to protein stability through his study of 22 proteins (Pace et al. 2011). Hydrophobic interaction is also presumably a basis for the disparate thermostability between two adenylate kinases sharing $78 \%$ sequence identity (Criswell et al. 2003). More hydrophobic interactions (within $5 \AA$ ) were found in Lac2 compared with Lac7 (438 vs. 396), which might lead to higher thermostability of Lac2.

The MD simulation of the two laccases also shined light on the molecular determinants of Lac2 thermostability. The overall RMSD value of Lac2 were lower than that of Lac7, indicating the whole flexibility of Lac2 was smaller than Lac7 (Fig. 7a). Comparison of the RMSF values of the two laccases revealed regions with significantly higher RMSF values in Lac7 than in Lac2 (Fig. 7b), especially the $180^{\text {th }}$ residue near the substrate-binding loop B1-B2, 267th residue in B7-B8 and 334th residue in $\mathrm{C} 1-\mathrm{C} 2$, corroborating the lower flexibility and higher stability of Lac2. Residues 98-102, upstream to the fungal laccase signature domain L2, were associated with lower RMSF values in Lac2, meaning they might help maintain the rigidity of the L2. Regions 262-273 and 331-342 corresponded to substrate-binding loops B7-B8 and $\mathrm{C} 1-\mathrm{C} 2$, respectively, they showed higher RMSF values in Lac7 than in Lac2. A unique salt bridge in Lac2, His326-Asp340, flanking the substrate-binding loop $\mathrm{C} 1-\mathrm{C} 2$, might contribute to lower the flexibility around loop C1-C2 in Lac2, whereas the majority of other salt 

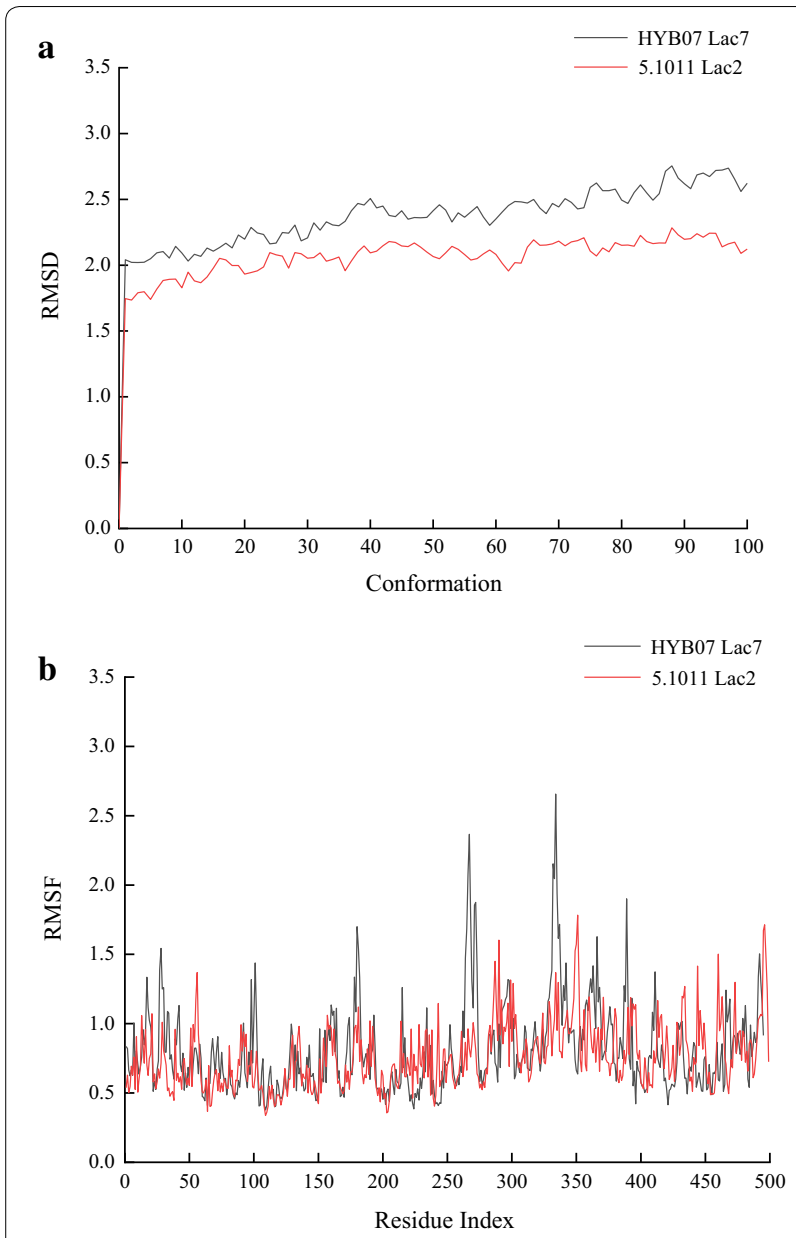

Fig. 7 Molecular Simulation of Lac2 from C. unicolor CGMCC 5.1011 and Lac7 from Cerrena sp. HYB07. a RMSD values of the laccases. $\mathbf{b}$ RMSF values of the laccases

bridges in the two proteins were conserved (Additional file 1: Table S5). Meanwhile, region 366-389 in Lac7 overlapped with the substrate-binding loop C4-C5 and neighbored the conserved laccase signature domain L3, with residues 384-389 in loop C4-C5 (Additional file 1: Fig. S5). The RMSF values, 1.9009 for Leu389 in Lac7 and 0.9833 for Ile393 in Lac2 (Fig. 7b), indicated that the region might also offer rigidity to protect the Lac2 active site against heat. The above findings suggested higher rigidity in various substrate-binding loops as well as conserved laccase signature domains in Lac2 allows it to retain more activity under high temperatures.

In summary, a white-rot fungal strain C. unicolor CGMCC 5.1011 achieved a maximum activity of 121.7 $\mathrm{U} / \mathrm{mL}$ after fermentation for $15 \mathrm{~d}$. Strain CGMCC 5.1011 contained 12 laccase isozymes, and a major laccase, Lac2, was purified from the fermentation broth. Lac2 was reactive over a wide range of temperatures, was $\mathrm{pH}$ - and temperature-stable and tolerant of organic solvents. Lac2 decolorized MG whereas a less thermostable laccase failed, corroborating the thermostability and operational stability of this novel laccase. High-level glycosylation and structural rigidity might account for the high stability of Lac2.

\section{Supplementary information}

Supplementary information accompanies this paper at https://doi. org/10.1186/s13568-020-01118-z.

Additional file 1. Additional figures and tables.

\section{Acknowledgements}

Not applicable.

\section{Authors' contributions}

YY: investigation and draft preparation. GZ and YL: investigation. XX: methodology, reviewing and editing. JY: Conceptualization, methodology, and manuscript preparation. All authors read and approved the final manuscript.

\section{Funding}

The work was funded by National Natural Science Foundation of China (31671795)

Availability of data and materials

All the data were presented in the main paper.

\section{Ethics approval and consent to participate}

This article does not contain any studies with human participants or animals performed by any of the authors.

\section{Consent for publication}

Not applicable.

\section{Competing interests}

The authors declare that they have no conflict of interest.

\section{Author details}

${ }^{1}$ Fujian Key Laboratory of Marine Enzyme Engineering, College of Biological Sciences and Technology, Fuzhou University, Fuzhou 350116, Fujian, China.

${ }^{2}$ GRG Metrology \& Test Fuzhou Co., Ltd, Fuzhou 350003, Fujian, China.

Received: 9 September 2020 Accepted: 24 September 2020

Published online: 02 October 2020

\section{References}

Ai M, Wang F, Huang F (2015) Purification and characterization of a thermostable laccase from Trametes trogii and its ability in modification of kraft lignin. J Microbiol Biotechnol 25(8):1361-1370. https://doi.org/10.4014/ jmb.1502.02022

Altschul SG, Miller W, Myers EW, Lipman DJ (1990) Basic local alignment search tool. J Mol Biol 215:403-410. https://doi.org/10.1016/s0022 $-2836(05) 80360-2$

Arora DS, Sharma RK (2010) Ligninolytic fungal laccases and their biotechnological applications. Appl Biochem Biotechnol 160(6):1760-1788. https:// doi.org/10.1007/s12010-009-8676-y

Baldrian P (2006) Fungal laccases-occurrence and properties. FEMS Microbio Rev 30(2):215-242. https://doi.org/10.1111/j.1574-4976.2005.00010.x Bendtsen J, Nielsen H, Von-Heijne G, Brunak S (2004) Improved prediction of signal peptides: SignalP 3.0. J Mol Biol 340(4):783-795. https://doi. org/10.1016/j.jmb.2004.05.028

BIOVIA (2015) BIOVIA Discovery Studio, version 4.5, San Diego: Dassault Systèmes. 
Chen SC, Wu PH, Su YC, Wen TN, Wei YS, Wang NC, Chih-An H, Wa HJ, Lie-Fen S, Peds S (2012) Biochemical characterization of a novel laccase from the basidiomycete fungus Cerrena sp WR1. Protein Eng Des Sel. 11:11. https //doi.org/10.1093/protein/gzs082

Cho BP, Tianle Y, Blankenship LR, Moody JD, Mona C, Beland FA, Culp SJ (2003) Synthesis and characterization of $\mathrm{N}$-demethylated metabolites of malachite green and leucomalachite green. Chem Res Toxicol 16(3):285-294 https://doi.org/10.1021/tx0256679

Christensen N, Kepp K (2012) Accurate stabilities of laccase mutants predicted with a modified FoldX protocol. J Chem Inf Model 52(11):3028-3042. https://doi.org/10.1021/ci300398z

Couto SR, Herrera JLT (2006) Industrial and biotechnological applications of laccases: A review. Biotechnol Adv 24(5):500-513. https://doi. org/10.1016/j.biotechadv.2006.04.003

Couto SR, Toca-Herrera JL (2007) Laccase production at reactor scale by filamentous fungi. Biotechnol Adv 25(6):558-569. https://doi.org/10.1016/j. biotechadv.2007.07.002

Criswell AR, Bae E, Stec B, Konisky J Jr, GNP, (2003) Structures of thermophilic and mesophilic adenylate kinases from the genus methanococcus. J Mol Biol 330(5):1087-1099. https://doi.org/10.1016/s0022-2836(03)00655-7

Edouard DC, Sigrist CJ, Alexandre G, Virginie B, Langendijk-Genevaux PS, Elisabeth G, Amos B, Nicolas H (2006) ScanProsite: detection of PROSITE signature matches and ProRule-associated functional and structural residues in proteins. Nucleic Acids Res 34(Web server):W362-W5. https:// doi.org/10.1093/nar/gkl124

Garg N, Bieler N, Kenzom T, Chhabra M, Ansorge-Schumacher M, Mishra S (2012) Cloning, sequence analysis, expression of Cyathus bulleri laccase in Pichia pastoris and characterization of recombinant laccase. J BMC Biotechnol 12(1):75. https://doi.org/10.1186/1472-6750-12-75

Hilden K, Hakala T, Lundell T (2009) Thermotolerant and thermostable laccases. Biotechnol Lett 31(8):1117-1128. https://doi.org/10.1007/s1052 9-009-9998-0

Ji Z, Lei S, Hao Z, Shufang W, Xiaoyu Z, Anli G, Travis B (2018) A novel homodimer laccase from Cerrena unicolor BBP6: Purification, characterization, and potential in dye decolorization and denim bleaching. PLoS ONE 13(8):e0202440. https://doi.org/10.1371/journal.pone.0202440

Kelley LA, Mezulis S, Yates CM, Wass MN, Sternberg MJ (2015) The Phyre2 web portal for protein modeling, prediction and analysis. Nat Protoc 10(6):845-858. https://doi.org/10.1038/nprot.2015.053

Lam WT (2016) PyMOL mControl: Manipulating molecular visualization with mobile devices. Biochemistry 45(1):76. https://doi.org/10.1002/ bmb.20987

Li W (2017) Molecular regulation mechanism of high-yield laccase in Cerrena sp. HYB07. Master's thesis, Fuzhou University

Manuel MR, Liu WC, Jeng WY, Lee CC, Hsu CA, Wen TN, Wang AH, Shyur LF (2015) Structural and functional roles of glycosylation in fungal laccase from Lentinus sp. PLoS ONE 10(4):e0120601. https://doi.org/10.1371/journ al.pone. 0120601

Michniewicz A, Ullrich R, Ledakowicz S, Hofrichter M (2006) The white-rot fungus Cerrena unicolor strain 137 produces two laccase isoforms with different physico-chemical and catalytic properties. Appl Microbiol Biotechnol 69(6):682-688. https://doi.org/10.1007/s00253-005-0015-9

Pace CN, Fu H, Fryar KL, Landua J, Trevino SR, Shirley BA, Hendricks MN, limura S, Gajiwala K, Scholtz JM (2011) Contribution of hydrophobic interactions to protein stability. J Mol Biol 408(3):514-528. https://doi.org/10.1016/j. jmb.2011.02.053

Piscitelli A, Giardina P, Lettera V, Pezzella C, Sannia G, Faraco V (2011) Induction and transcriptional regulation of laccases in fungi. Curr Genomics 12(2):104-112. https://doi.org/10.2174/138920211795564331

Shental-Bechor D, Levy Y (2008) Effect of glycosylation on protein folding: a close look at thermodynamic stabilization. Proc Natl Acad Sci USA 105(24):8256-8261. https://doi.org/10.1073/pnas.0801340105

Sievers F, Wilm A, Dineen D, Gibson T, Karplus K, Li W (2011) Fast, scalable generation of high-quality protein multiple sequence alignments using Clustal Omega. Mol Syst Biol 7:539. https://doi.org/10.1038/msb.2011.75

Slomczynski D, Nakas J, Tanenbaum S (1995) Production and characterization of laccase from Botrytis cinerea 61-34. Appl Environ Microbiol 61(3):907912. https://doi.org/10.1016/S0020-7403(99)00103-4
Songulashvili G, Jimenéz-Tobón GA, Jaspers C, Penninckx MJ (2012) Immobilized laccase of Cerrena unicolor for elimination of endocrine disruptor micropollutants. Fungal Biol 116(8):883-889. https://doi.org/10.1016/j. funbio.2012.05.005

Tamura K (2011) MEGA5: molecular evolutionary genetics analysis using maximum likelihood, evolutionary distance, and maximum parsimony methods. Mol Biol Evol 28:2731-2739. https://doi.org/10.1093/molbev/ msr121

Tina K, Bhadra R, Srinivasan N (2007) PIC: Protein Interactions Calculator. Nucleic Acids Res 35:W473-W476. https://doi.org/10.1093/nar/gkm423

Vite-Vallejo O, Palomares LA, Dantán-González E, Ayala-Castro HG, MartínezAnaya C, Valderrama B, Folch-Mallol J (2009) The role of N-glycosylation on the enzymatic activity of a Pycnoporus sanguineus laccase. Enzyme Microb Technol 45(3):233-239. https://doi.org/10.1016/j.enzmi ctec.2009.05.007

Wu M-H, Lee C-C, Hsiao A-S, Yu S-M, Wang AH, Ho T-HD (2018) Kinetic analysis and structural studies of a high-efficiency laccase from Cerrena sp. RSD1. FEBS Open Bio 8(8):1230-1246. https://doi.org/10.1002/2211-5463.12459

Xu X, Huang X, Liu D (2018) Inhibition of metal ions on Cerrena sp. laccase: Kinetic, decolorization and fluorescence studies. J Taiwan Inst Chem Eng 84:1-10. https://doi.org/10.1016/j.jtice.2017.12.028

Yang J, Li W, Ng T, Deng X, Lin J, Ye X (2017a) Laccases: production, expression regulation, and applications in pharmaceutical biodegradation. Front Microbiol 8:832. https://doi.org/10.3389/fmicb.2017.00832

Yang J, Lin Q, Ng T, Ye X, Lin J (2014) Purification and characterization of a novel laccase from Cerrena sp. HYBO7 with dye decolorizing ability. PLOS One 9(10):e110834. https://doi.org/10.1371/journal.pone.0110834

Yang J, Lin Y, Yang X, Ng TB, Lin J (2016a) Degradation of tetracycline by immobilized laccase and the proposed transformation pathway. J Hazard Mater 322(Pt B):525-531. https://doi.org/10.1016/j.jhazmat.2016.10.019

Yang J, Wang G, Ng TB, Lin J, Ye X (2015) Laccase production and differential transcription of laccase genes in Cerrena sp in response to metal ions, aromatic compounds, and nutrients. Front Microbiol 6(2):123-128. https ://doi.org/10.3389/fmicb.2015.01558

Yang J, Wang Z, Lin Y, Ng T, Ye X, Lin J (2017) Immobilized Cerrena sp. laccase: preparation, thermal inactivation, and operational stability in malachite green decolorization. Sci Rep 7(1):16429. https://doi.org/10.1038/s4159 8-017-16771-x

Yang J, Xu X, Ng T, Lin J, Ye X (2016) Laccase gene family in Cerrena sp. HYB07: Sequences, heterologous expression and transcriptional analysis. Molecules 21(8):1017. https://doi.org/10.3390/molecules21081017

Yang J, Xu X, Yang X, Ye X, Lin J (2016) Cross-linked enzyme aggregates of Cerrena laccase: Preparation, enhanced $\mathrm{NaCl}$ tolerance and decolorization of Remazol Brilliant Blue Reactive. J Taiwan Inst Chem Eng 65:1-7. https:// doi.org/10.1016/j.jtice.2016.04.025

Yang J, Yang X, Lin Y, Ng T, Lin J, Ye X (2015) Laccase-catalyzed decolorization of malachite green: Performance optimization and degradation mechanism. PLoS ONE 10(5):e0127714. https://doi.org/10.1371/journal.pone.0127714

Yang J, Yang X, Ye X, Lin J (2016) Optimal parameters for laccase-mediated destaining of Coomassie Brilliant Blue R-250-stained polyacrylamide gels. Data Brief 7:1-7. https://doi.org/10.1016/j.dib.2016.01.029

Yang X, Wu Y, Yan J (2020) A thermo-active laccase isoenzyme from Trametes trogii and its potential for dye decolorization at high temperature. Front Microbiol. https://doi.org/10.3389/fmicb.2020.00241

Zoya Alexandrovna L, Alexander Viktorovich L, Alexey Arkadievich L (2010) Two laccase isoforms of the basidiomycete Cerrena unicolor VKMF-3196 Induction, isolation and properties. J Basic Microbiol 50(1):72-82. https:// doi.org/10.1002/jobm.200900382

\section{Publisher's Note}

Springer Nature remains neutral with regard to jurisdictional claims in published maps and institutional affiliations. 